\title{
The Correlation Between Malondialdehyde Serum Levels and the Duration of Sun Exposure; and Melasma Area and Severity Index in Patients with Melasma in Makassar
}

\author{
Fadlina Zainuddin ${ }^{1,}$, , Anis Irawan Anwar ${ }^{1}$, Khairuddin Djawad $^{1}$, Arifin Seweng², \\ Rizalinda Sjahril $^{3}$, Anni Adriani ${ }^{1}$ \\ ${ }^{1}$ Department of Dermatology, Medical Faculty, Hasanuddin University, Makassar, Indonesia \\ ${ }^{2}$ Department of Biostatistic, Faculty of Public Health, Hasanuddin University, Makassar, Indonesia \\ ${ }^{3}$ Department of Microbiology, Medical Faculty, Hasanuddin University, Makassar, Indonesia
}

Email address:

drfadlina@gmail.com (F. Zainuddin)

${ }^{*}$ Corresponding author

\section{To cite this article:}

Fadlina Zainuddin, Anis Irawan Anwar, Khairuddin Djawad, Arifin Seweng, Rizalinda Sjahril, Anni Adriani. The Correlation Between Malondialdehyde Serum Levels and the Duration of Sun Exposure; and Melasma Area and Severity Index in Patients with Melasma in Makassar. American Journal of Clinical and Experimental Medicine. Vol. 4, No. 3, 2016, pp. 68-75. doi: 10.11648/j.ajcem.20160403.16

Received: April 21, 2016; Accepted: May 3, 2016; Published: May 13, 2016

\begin{abstract}
Ultraviolet (UV) plays an important role in the pathogenesis of melasma. Ultraviolet rays can cause lipid peroxidation in cell membranes that trigger the generation of free radicals that can stimulate melanocytes to produce many melanin. Malondialdehyde (MDA) is the end product of lipid peroxidation in the body. MDA is an important indicator of lipid peroxidation. There are a lot of research has been done in linking MDA to the severity of melasma. But there has not yet any research connecting it with sun exposure in patients with melasma. This study aims to find out the relationship between MDA serum levels and the duration of sun exposure; and Melasma Area and Severity Index (MASI) scores in patients with melasma. The research method was the case control study. It used 84 samples divided into two groups: a melasma group consisting of 42 people and a control group consisting of 42 people. The examination was performed with anamnesis, questionnaires, duration score of sun exposure, physical examination and the assessment of MDA serum levels with Thiobutiric acid-reactive substance test reaction. The data were analysed using independent $t$ test, Mann Whitney, and Spearman correlation test. The results show that there is a significant correlation between the levels of MDA with the duration of sun exposure, but the duration of sun exposure is not associated with MASI score. It means that MDA levels are not significantly associated with MASI scores. Free radicals are significantly associated with the duration of sun exposure, but the severity of melasma is not affected by the duration of sun exposure. The severity level of melasma is still much influenced by some other risk factors associated with the pathogenesis of melasma.
\end{abstract}

Keywords: Length Sun Exposure, Melasma, Malondialdehyde, MASI Scores

\section{Introduction}

Melasma is a common pigmentation disorder that most often occurs and manifests as macular hyperpigmentation of the skin exposed to the sun. [1] Although it can occur in men and women as well as on a variety of skin types, melasma most often occurs in women of reproductive age with Fitzpatrick skin types IV -VI. [1,2]

Melasma basically can affect all races, particularly for those who live in areas of high exposure to sunlight (tropical climates). [3] Majority of incident was suffered by women with darker skin colour type (Fitzpatrick skin type III, IV, V, and VI) and some ethnic groups, which are Latin, AfricanAmericans, African-Caribbean and Asian. [4] Not only women, melasma can also be found in men $( \pm 10 \%)$. [3, 5, 6] In Indonesia, the ratio of cases of women and men is 24:1. Mainly seen in women of childbearing age with a history of frequent long exposure to direct sunlight. The incidence is 
highest at ages 25-44 years old. [3]

The pathogenesis of melasma remains unknown for certain. [7] Ultraviolet radiation (UV) plays an important role in the pathogenesis of melasma. Exposure to constant UV radiation on skin can produce Reactive Oxygen Species (ROS) and this significantly increases oxidative stress in cells. The generation of free radicals produced by oxidative stress interacts with all the essential components in the cell such as lipids, proteins, DNA, carbohydrates and enzymes. Interactions with lipid membranes to produce plasma lipid peroxidation in cellular membranes releasing diacylglycerol (DAG) then activates protein kinase $\mathrm{C}$ beta $(\mathrm{PKC}-\beta)$ to stimulate melanogenesis through tyrosinase activation. [8]

Oxidative stress plays an important role in a variety of chronic and degenerative diseases. Reactive Oxygen Species (ROS) can chemically alter all functions and biomolecular structures (lipids, proteins and nucleic acids). [9] On melasma, ultraviolet rays can cause lipid peroxidation in cell membranes that trigger the generation of free radicals that can stimulate the melanocytes to produce more melanin. [7] Malondialdehyde (MDA) is a dialdehydes compound which is the end product of lipid peroxidation in the body. MDA is an important indicator of lipid peroxidation. [10]

Research by Hamadi et al. (2009) showed a strong positive correlation between levels of MDA serum with MASI value. In this study, the levels of MDA and MASI value measured before administration of melatonin therapy was a powerful antioxidant. Then MDA levels were measured after 45, 90 and 120 days of therapy. MASI value were measured again after 15 and 120 days of therapy. In this study, there was a significant positive strong correlation between MASI impairment and decreased levels of MDA $(r=0.78, p<0.01)$. This study further correlates the role of oxidative stress in which the MDA as one of the indicator in terms of the incidence and severity of melasma degrees measured using MASI. [11]

Research by Seckin et.al (2013) measured levels of MDA serum from 50 melasma patients and 50 healthy volunteers. Diagnosis melasma clinically evaluated based Melasma Area and Severity Index (MASI). The study matches MASI average score is $21.54 \pm 8.84$, MDA serum levels were significantly higher $(\mathrm{p}<0.001)$ in patients with melasma compared with the control group. The results showed a balance between oxidants and anti-oxidants have been disrupted and oxidative stress increased on melasma. [12]

The study by Sari et al (2014) showed a positive correlation between levels of MDA serum with MASI value in patients with melasma, with a coefficient correlation value of $\mathrm{r}$ : 0913, and $\mathrm{p}<0.001$. Additionally MDA serum levels obtained in subjects with melasma is higher $(0.4737 \pm$ $0.18594 \mu \mathrm{M} / \mathrm{L})$ compared to subjects with no melasma $(0.2459 \pm 0.5871 \mu \mathrm{M} / \mathrm{L})$, with $\mathrm{p}<0.001$. It shows the relationship between melasma and oxidative stress increases the understanding of the etiology and pathogenesis of melasma and therapy. [13]

\section{Material and Methods}

\subsection{Patient and Clinical Evaluations}

Table 1. Duration Score of Sun Exposure.

\begin{tabular}{|c|c|c|}
\hline Category & Type & Score \\
\hline \multicolumn{3}{|l|}{ 1. Occupation } \\
\hline - High risk & Fisherman & 3 \\
\hline - Intermediate risk & $\begin{array}{l}\text { Farmers, farm workers, farmers, forest workers, building or } \\
\text { construction worker, members of TNI / Polri }\end{array}$ & 2 \\
\hline - Low risk & Government Empoyee / private employee, Student, Housewife & 1 \\
\hline \multicolumn{3}{|c|}{ 2. Long activity under the sun } \\
\hline - High risk & $>2.5$ hours & 3 \\
\hline - Intermediate risk & $>30$ minutes $-2,5$ hours & 2 \\
\hline - Low risk & $5 \min -30$ mins & 1 \\
\hline \multicolumn{3}{|c|}{ 3. The intensity of the activity under the sun at peak sun hours ( $10 \mathrm{am}$ to $2 \mathrm{pm})$} \\
\hline - High risk & Always & 3 \\
\hline - Intermediate risk & Sometime & 2 \\
\hline - Low risk & Never & 1 \\
\hline \multicolumn{3}{|c|}{ 4. Activity while on vacation / recreation } \\
\hline - High risk & Swimming, sunbate on the beach, fishing, & 3 \\
\hline - Intermediate risk & Cycling, outdoor sport & 2 \\
\hline - Low risk & Stay at home, trips to the mall, an indoor sports & 1 \\
\hline \multicolumn{3}{|c|}{ 5. The use of photoprotection } \\
\hline - High risk & Never & 3 \\
\hline - Intermediate risk & Sometime & 2 \\
\hline - Low risk & Always & 1 \\
\hline AMOUNT & & \\
\hline
\end{tabular}


The melasma group was composed of 42 patients who applied to the Dermatology Outpatient Clinic of Hasanuddin University Hospital, Labuang Baji Hospital, and Andalas Primary Healthcare, during the period of January to March 2016 who were diagnosed with melasma. The control group was composed of 42 healthy volunteers. The diagnoses were based on the clinical presentations, wood lamp, and dermatoscopic examination. Each patient with melasma was evaluated by MASI score. The control group was chosen among healthy volunteers who have normal physical examination, and have not any lesion on her face. The all participants have skin type between IV and V; . with range of age between 20-49 years old. The all participants who was pregnant, using hormonal contraception, immunocopromised or having any chronic illness, (liver-kidney disease, heart disease, hypertension, diabetes, malignancy and familial hypercholesterolemias), and have chronic inflammatory disease of the skin (acne, atopy, psoriasis, and vitiligo) were not included in the study. The all participants of the study were chosen among individuals who were not cigarette smoker or alcohol user and had not ingest vitamins $\mathrm{E}$ and $\mathrm{C}$, selenium, zinc or iron for the last three weeks. The ethical committee of Hasanuddin University Medical Faculty approved the study and all participants were informed about the study. All demographical information of the participants was recorded.

For the assessment of the duration of sun exposure in patients with melasma subject group and the control group were calculated based on the duration score of sun exposure as seen in table 1 .

\subsection{Measurement of Melasma Severity}

The melasma severity was measured by Melasma Area and Severity Index (MASI). MASI score was determined by the degree of melasma in each region (forehead, regio malar right, regio malar left, and chin) which was assessed by three variables: the percentage of the total area involved (A), the level of darkness (D), and homogeneity (H). The total percentage of area involved (A) was divided into: $0=$ no; $1=$ $<10 \%$ area,; $2=10-29 \%$ area; $3=30-49 \%$ area; $4=50-69 \%$ area; $5=70-89 \%$ area; and $6=90-100 \%$ area. The darkness of melasma (D) compared with normal skin and graded on a scale from 0 to 4: $0=$ normal skin color without evidence of hyperpigmentation; 1 = barely visible hyperpigmentation; 2 = mild hyperpigmentation; 3 = moderate hyperpigmentation; 4 $=$ severe hyperpigmentation. Homogeneity hyperpigmentation $(\mathrm{H})$ are also assessed on a 0 to $4: 0=$ normal skin color without hyperpigmentation; $1=$ there are points hyperpigmentation (specks); $2=$ small area (small patchy) with a diameter $<1.5 \mathrm{~cm} ; 3=$ area involved with a diameter $>2 \mathrm{~cm} ; 4=$ skin involved the same without a clear area. [14]

MASI value was calculated by the amount of the darkness (D) and homogeneity $(\mathrm{H})$ multiplied by the numerical value of the area involved (A) and the percentage of the four facial areas (10-30\%). The total value of MASI: forehead $0.3(\mathrm{D}+$ $\mathrm{H}) \mathrm{A}+$ right malar $0.3(\mathrm{D}+\mathrm{H}) \mathrm{A}+$ left malar $0.3(\mathrm{D}+\mathrm{H}) \mathrm{A}$ chin $+0.1(\mathrm{D}+\mathrm{H})$ A total score ranging from 0 to 48 . [15]

\subsection{Measurement of MDA Serum with Thiobarbituric Acid-Reactive Substance Levels}

The MDA serum levels were determined by a method based on the reaction with thiobarbituric acid (TBA) at 90$100^{\circ} \mathrm{C}$. In the TBA test reaction, MDA or MDA-like substances and TBA react together for production of a pink pigment having an absorption maximum at $532 \mathrm{~nm}$. Each MDA-containing samples and standards are examined in the form of duplication. Each $100 \mathrm{~mL}$ of sample and MDA standard solution was added and then separated in mikrosentrifuge tube. Then $100 \mathrm{uL}$ SDS lysis solution added to each sample and MDA standard solution, and then mixed thoroughly and then samples were incubated for $5 \mathrm{~min}$ at room temperature. Furthermore TBA $250 \mathrm{~mL}$ reagent is added to each sample and standards to be examined. Each tube was closed and incubated at $95^{\circ} \mathrm{C}$ for $45-60$ minutes. The tube was removed and cooled to room temperature in the freezer for 5 minutes. All standard and sample tube centrifuged at $3000 \mathrm{rpm}$ for 15 minutes. Supernatant of 200 $\mathrm{mL}$ of sample and standard solution MDA transferred to 96 well microplate in accordance with Spectrophotometric plate reader. Duplication of each sample and standard were read. Absorbance readings were taken at $490 \mathrm{~nm}$. The results were expressed as $\mathrm{mmol} / \mathrm{L}$ according to a standard graphics, which was prepared with serial dilutions of standard 1,1,3,3tetramethoxypropane

\subsection{Data analysis}

The data obtained were analysed through the Statistical Product And Service Solutions (SPSS). Data distribution were tested using the Kolmogorov-Smirnov test. Mannwhitey test and t-test were employed for not normal and normal data distribution respectively. The statistical test used Spearman correlation test to assess correlation between MDA with a duration of sun exposure with MASI score where $p$ $<0.05$ was considered significant.

\section{Result}

From Table 2 it can be seen that the percentage of patients with melasma was higher at age $>40$ years in 32 samples $(76.2 \%)$, with most of them, work in the room which is 35 samples $(83.3 \%)$. Most of samples had skin type IV in 34 subjects $(80.9 \%)$, with most of the pattern of melasma is the malar pattern in 25 samples $(59.5 \%)$, and types of epidermal melasma is the most types in 33 samples (78.6\%). Most of dermoscope patterns showed annular shaped pattern, brown, with follicular opening and telangiectasia as many as 24 samples $(57.1 \%)$ 
Table 2. Characteristics of the sample.

\begin{tabular}{|c|c|c|c|}
\hline Characteristics & Melasma $n=42(\%)$ & Control $n=42(\%)$ & Total \\
\hline \multicolumn{4}{|l|}{ Age } \\
\hline$<30$ years & $2(4.8)$ & $11(26.2)$ & $13(15.5)$ \\
\hline $30-39$ years & $8(19)$ & $19(45.2)$ & $27(32.1)$ \\
\hline$>40$ years & $32(76.2)$ & $12(28.6)$ & $44(52.4)$ \\
\hline Occupation & & & $61(72.6)$ \\
\hline Indoor & $35(83.3)$ & $26(61.9)$ & $23(27.4)$ \\
\hline Outdoors & $7(16.7)$ & $16(381)$ & \\
\hline \multicolumn{4}{|l|}{ Skin types } \\
\hline IV & $34(80.9)$ & $33(78.6)$ & $67(79.7)$ \\
\hline $\mathrm{V}$ & $8(19.1)$ & $9(21.4)$ & $17(20.3)$ \\
\hline \multicolumn{4}{|l|}{ pattern of Melasma } \\
\hline Centrofacial & $17(40.5)$ & - & \\
\hline Malar & $25(59.5)$ & - & \\
\hline \multicolumn{4}{|l|}{ Type of Melasma } \\
\hline epidermal & $33(78.6)$ & - & \\
\hline mixed & $9(21.4)$ & - & \\
\hline \multicolumn{4}{|l|}{ Pattern of dermoskop } \\
\hline Annular pattern, brown, follicular opening, & $9(21.4)$ & - & \\
\hline Annular pattern, brown, follicular opening, telengiektasis & $4(57.1)$ & - & \\
\hline Annular pattern, brown, grayish,follicular opening & $2(4.7)$ & - & \\
\hline $\begin{array}{l}\text { Annular pattern, brown, grayish, follicular opening, } \\
\text { telengiektasis }\end{array}$ & $7(16.7)$ & - & \\
\hline
\end{tabular}

Table 3. Comparison of the duration score of sun exposure with levels of MDA.

\begin{tabular}{llllll}
\hline Variable & Group & N & Mean & SD & P \\
\hline \multirow{2}{*}{ Score Exposure Duration $^{-1}$} & melasma & 42 & 8.0 & 1.4 & .116 \\
& Control & 42 & 8.5 & 1.9 & 17.7 \\
MDA $^{-2}$ & melasma & 42 & 88.8 & 86.5 & 17.5 \\
\hline
\end{tabular}

${ }^{1}$ Mann-Whitney test

${ }^{2}$ Independent $\mathrm{t}$ test

Table 3 shows that no significant difference in scores between the duration of sun exposure in melasma and control group ( $p>0.05$ ). There is no significant difference in MDA levels between the two groups ( $p>0.05)$, but it appears that the levels of MDA in melasma is higher than controls, ie 88.8 to 86.5 .

Table 4. Correlation the duration score of sun exposure at all levels of MDA subject.

\begin{tabular}{llll}
\hline Type & Variable & Statistical & MDA \\
\hline \multirow{2}{*}{ Spearman's } & Score & Correlation Coefficient $(\mathrm{R})$ & 0.428 \\
rho & Duration & P & 0,000 \\
& Exposure & N & 84 \\
\hline
\end{tabular}

Spearman Correlation'S

Table 4 shows a significant positive correlation between the duration score of exposure to sunlight with MDA levels ( $p<0.001$ ), where the higher the score, the higher the duration of exposure to MDA. Great correlation between the two is moderate $(\mathrm{R}=0.428)$ as shown in Figure 1

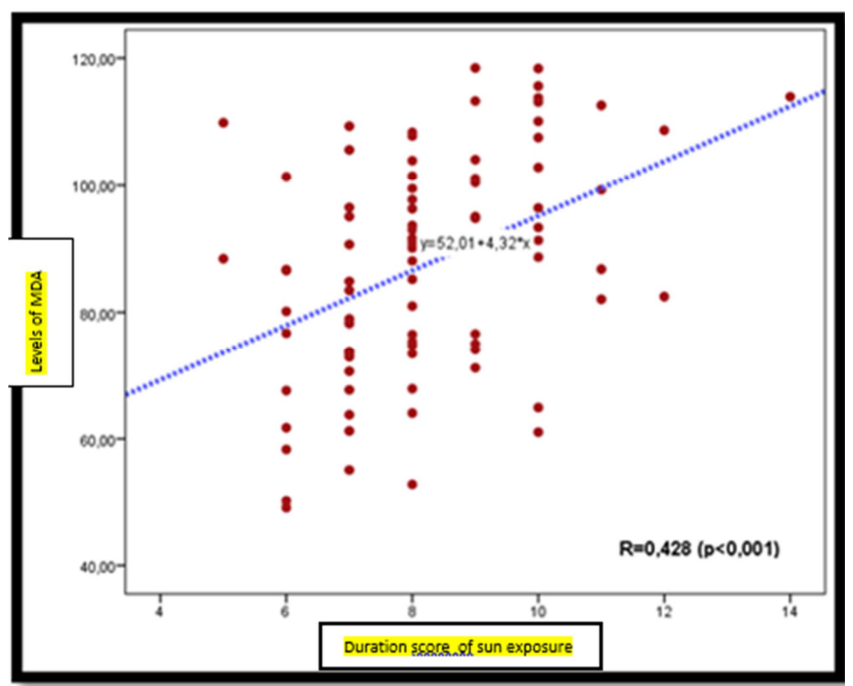

Figure 1. Correlation the Duration Score of Sun Exposure to MDA levels in All Subjects. 
Table 5. Correlation the duration score of sun exposure with levels of MDA by group.

\begin{tabular}{lllll}
\hline Type & Group & Variable & Statistical & MDA \\
\hline & & Score & Correlation & \\
& \multirow{2}{*}{ Melasma } & Duration & Coefficient (R) & .669 \\
& & Exposure & N & 0,000 \\
Spearman's & & & Correlation & 42 \\
rho & & Score & Coefficient (R) & 0,302 \\
& \multirow{2}{*}{ Control } & Duration & P & 0.052 \\
& & Exposure & N & 42 \\
\hline
\end{tabular}

Spearman Correlation'S

Table 5 shows that in group of Melasma, there is a significantly positive correlation between the duration score of exposure to sunlight with MDA levels ( $p<0.001$ ), where the higher the score, the higher the duration of exposure to MDA. The correlation between the two is strong $(\mathrm{R}=0.669)$, while In the control group, there is no significant correlation between the score of the duration of exposure to MDA levels ( $p>0.05)$. However, there is a tendency of increasing MDA as the duration of sun exposure increases.

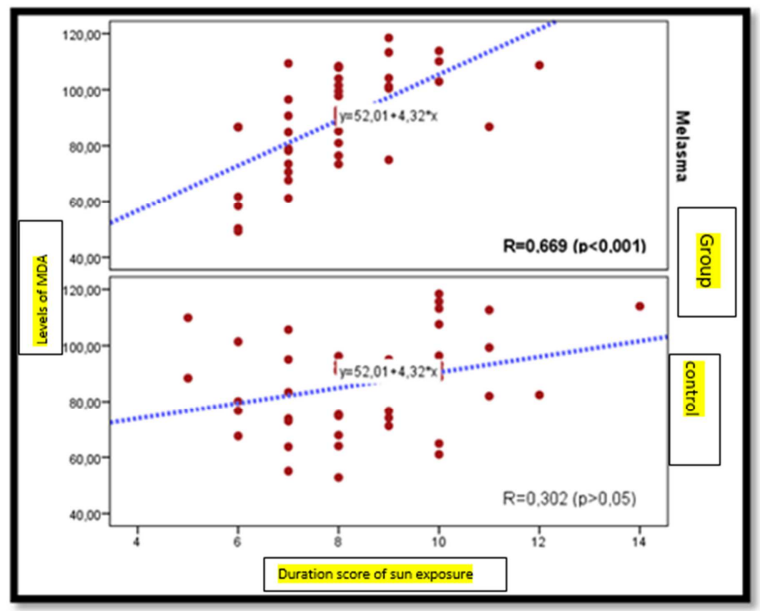

Figure 2. Correlation the Duration score of Sun Exposure to MDA levels by Group.

Table 6. Correlation of MDA, the duration score of sun exposure and MASI score.

\begin{tabular}{|c|c|c|c|c|}
\hline Type & Variable & Statistical & $\begin{array}{l}\text { Score Duration } \\
\text { Exposure }\end{array}$ & MDA \\
\hline $\begin{array}{l}\text { Spearman's } \\
\text { rho }\end{array}$ & $\begin{array}{l}\text { MASI } \\
\text { score }\end{array}$ & $\begin{array}{l}\text { Correlation } \\
\text { Coefficient (R) } \\
\text { P }\end{array}$ & $\begin{array}{l}-0.003 \\
983\end{array}$ & $\begin{array}{c}0.092 \\
563\end{array}$ \\
\hline
\end{tabular}

Spearman's Correlation

Table 6 shows that there is no significant correlation between the duration of sun exposure with MASI scores ( $p>$ 0.05 ) and no significant correlation between the scores MASI with MDA levels ( $p>0.05$ ). However, there is a tendency that the higher score of MASI, the higher level of MDA.

\section{Discussion}

The study involved 42 subjects with melasma and 42 subjects with no melasma as control group.

Based on age category, the incidence of melasma is higher at age $>40$ years 32 samples $(76.2 \%)$ as shown in Table 2 . Average melasma subjects was 39 years old, the minimum age is 22 years and maximum age 49 years. This study was supported by research Sari, et al (2014) in which distribution is the largest age group of 41-50 years with a lifespan of as much as $41.2 \%$. [13] Research conducted by Ortonne et al. (2009) in the nine clinics scattered around the world obtained an average age group was $42.9 \pm 9.6$ melasma, in the United States of $45.0 \pm 10.7,41.0 \pm 7.46$ in France, in Germany 35.1 \pm 7.18 , in the Netherlands was $40.7 \pm 8.86,39.5 \pm 7.77$ in Mexico, in Italy $41.3 \pm 5.91,48.7 \pm 6.71$ in Singapore, in Korea South $37.5 \pm 9.33$ and $48.7 \pm 7.83$ Hong Kong. [16]

Based on occupation category, most of the subjects with melasma have indoor jobs (83.3\%). This findings is in line with research by Rikyanto (2004) in Yogyakarta that shows most of people $(57,3 \%)$ with melasma are a civil servant. [17] Civil servant in Indonesia mostly work indoor. These studies are also accordance to research by Tia Febrianti, et al., (2004) in Cipto Mangunkusumo Hospital, Jakarta that suggests $45,52 \%$ of people with melasma are house wives. We recommend this type of work should be distinguished based on indoor or outdoor, length of exposure to sunlight during the day, and protection against sunlight (eg, types of clothing, umbrellas and hats). [18] The type of work is important to understand and evaluate melasma cases that are associated with outdoors activities. Type of work can also potray the daily needs to look beautiful, and thus the use of cosmetics that sometimes can be one of the factor in the melasma. [17] Material cosmetics that cause hyperpigmentation / melasma are derived from irritants or photosensitizer e.g. bergamot oil, tar, some fatty acids, mineral oil, petrolatum, beeswax, dyes such as Sudan III, para-phenylene diamine, fragrances, and preservatives cosmetics. [4]

Most pattern of Melasma found in this study is the malar by 25 people $(59.5 \%)$ followed by centrofacial patterns by 17 subjects $(40.5 \%)$ and no mandibular pattern was found. This is consistent with research by Tia Febrianti, et.al., (2004) in Cipto Mangunkusumo Hospital found 97 people (66.90\%) with malar pattern, 42 people $(28.96 \%)$ with centrofacial pattern and found no pattern of mandibular $(0 \%)$. [18] Based on the literature, the clinical picture of melasma is divided into three forms, namely forms centrofacial, malar, and mandibular. In centrofacial form, lesions covering the cheeks, forehead, nose, upper lip, and chin (63\%). In malar form, lesions on the cheeks and nose $(21 \%)$, while the shape of the mandibular, lesions of the ramus mandibular (16\%). [19] In this study there is no sample with mandibular pattern because besides it is epidemiologically most rare, melasma most often occurs on sun-exposed areas such as the forehead, nose, cheeks, chin and upper lip, whereas the mandibular areas rarely exposed to the sun.

Melasma can basically affect all races, particularly for those who live in areas with long exposure to sunlight (tropical climates). [3] The majority of cases happen to 
women of reproductive age with darker skin colour type, (skin types Fitzpatrick IV, V, and VI) and some ethnic groups as Latin, African-Americans, African-Caribbean and Asian. $[1,2,4]$ In this study, 34 people $(80.9 \%)$ patients with melasma have IV skin types

The type of melasma most commonly found in this study is the type of epidermal by 33 samples $(78.6 \%)$, followed by mixed type by 9 samples $(21.4 \%)$. Dermal type was not found in this study. This is consistent with research in Singapore which suggests that more than $2 / 3$ of cases are type epidermal melasma. [20] This study does not obtain the type of dermal therefore the type of dermal melasma mostly caused by hormonal factors such as pregnancy and use of hormonal contraception were excluded from this study.

Examination with light wood useful to know the type of melasma. [19] Ultraviolet light from Wood penetrates the stratum corneum and epidermis where melanin is distributed. Depth will determine fluorescence pigment. Thus, the type of epidermal pigmentation seen under Wood's lamp, whereas the type of dermal will seem less obvious or not exist under the lights compared with visible light. [21]

Dermoscopy is a non-invasive technique using optical equipment that enables variable magnification from 6 to 400X. Dermoscopy further demonstrate the pigmented cell groups, depending on the amount of pigment and depth. Pigmentation were observed mainly from the melanin and hemoglobin in the blood vessels. By inspection, the color depends on the quantity of melanin, or density, and location; black when located in the stratum corneum, with shades of brown in the lower layers of the skin, blue or bluish gray in the dermis. [21] Annular pattern (also known as pseudonetwork) can be seen on flat lesions. Annular pattern characterized by hypopigmentation circle small and follicular opening surrounded by varying amounts of pigment. [22] In Dermoscopy, considered a type of epidermal if brown with irregular pigmented network. Type dermal, if it looks bluish gray coloring, in which a network of pigment loss regularity; and mixed type, will appear the second picture above both epidermal and dermal. [21] This research use light wood and melasma dermoskop to determine the type of sample. In this study, dermoskop pattern in the form of an annular pattern, brown, and follicular opening is accompanied telengiektasis were most widely obtained as many as 24 samples (57.1\%). Because brown melanin pigment in the epidermis that is going to look increasingly clear that help classify the type of epidermal. As for the picture annular pattern, grayish brown, follicular opening provides mixed-type classification by the presence of melanin pigment in the epidermis are evident and there is also the pigment melanin in the dermis within perivascular macrophages so as to provide grayish brown color.Telengiectasis picture obtained in examinations dermoskop because melanocytes are also influenced by angiogenic factors which normal melanocytes express receptors for vascular endothelial growth factor (VEGF), so that in some types of melasma can be found erythema telengiectatic along with lesions. [23]

In this study, shown in Table 3, there were no significant differences between the duration score of sun exposure melasma with control group ( $p>0.05$ ). There is no significant difference in MDA levels between the two groups ( $p>0.05)$, but it appears that the levels of MDA in melasma higher than controls, ie 88.8 to 86.5 . Research by Sari, et al (2014) found a mean MDA serum levels in subjects with melasma significantly different from the subject instead of melasma with $\mathrm{p}<0.001$. MDA serum levels in subjects with melasma to be higher $(0.4737 \pm 0.18594 \mu \mathrm{M} / \mathrm{L})$ compared to subjects not melasma $(0.2459 \pm 0.5871 \mu \mathrm{M} / \mathrm{L})$. [13] In our study showed no significant on the difference between the levels of serum MDA and control groups melasma due to the duration score of sun exposure between the two did not differ significantly too far. In addition the results of this study are slightly different with the study by Sari, et al (2014) in Denpasar, Bali who found a significant difference level of MDA serum between melasma patients and controls. This difference is caused by the characteristics of the subject, which are the type of melasma and the age of the subjects. Research by Sari, et al (2014) found mixed type at the most and also other type, which is dermal, which the levels of MDA in both types is higher than the epidermal type, because of tissue damage is more widespread, and the biological activity of melanocytes are higher so they produce more free radicals. [4] In addition to the type of melasma, the study by Sari, et al (2014) does not restrict the age of the sample as in our study where we limit the age between 20-49 years old. MDA increases with age because as people grow old they are more exposed to the free radical agents. [24]

Melasma is often found in areas that are exposed to sunlight. Exposure to sunlight is the primary originator of melasma. It causes lipid peroxidation in cellular membrane which produces free radicals that stimulate melanogenesis. Additionally, keratinocytes after exposure to ultraviolet light produced some alpha mediators such as interleukin (ILalpha) and endothelin-1 (ET-1), which stimulate melanogenesis. [8, 12] This suggests that elevated levels of MDA in patients with melasma can be generated from increased oxidative stress and tissue damage.

As described in table 4, there is a significant positive correlation between the duration score of exposure to sunlight with MDA levels $(\mathrm{p}<0.001)$. Coefficient correlation between these two variables is moderate $(\mathrm{R}=0.428)$. This is consistent with research by Diaconu, et. al (2014) which found the MDA levels were significantly higher in the group with frequent exposure to the sun. The main oxidative stress generated by external factors, namely ultraviolet rays. [25]

UV radiation affects lipid (cell membrane component), thus releasing diacylglycerol (DAG), which activates the tyrosinase enzyme, resulting in increased melanogensis. Indirect effects of UV radiation is that it stimulates the synthesis and secretion of paracrine factors keratinocytes. Melanocytes adapt by increasing the number and change function. It is an all natural protection against sun exposure. [8] In the production of chemokines and induction of the inflammatory response, ROS are important mediators. [26] MDA is an end product of lipid peroxidation membrane and 
is one of a biomarker of oxidative stress. [12] In Table 5 is also evident that the group of Melasma, found a significant positive correlation between the duration score of exposure to sunlight with MDA levels ( $\mathrm{p}<0.001)$, where the higher the score, the higher the duration of exposure to MDA. Coefficient correlation between the two variables is strong $(\mathrm{R}$ $=0.669$ ), while in the control group, there were no significant correlation between the duration score of exposure to MDA levels ( $p>0.05$ ) but there is a tendency of increasing the duration of sun exposure, MDA has increased as well. The results of this study indicate that MDA levels in patients with melasma is more often produced by exposure to sunlight which produces oxidative stress and tissue damage.

In this study, found no significant correlation between the duration of sun exposure to the severity of melasma ( $\mathrm{p}>$ 0.05). (Table 6) This finding is accordance with Miranti, et al (2016) who did not find an association between exposure to the sun with the onset of melasma. [27] Etiopathogenesis of melasma is multifactorial and still unclear. Genetic and hormonal factors and ultraviolet exposure are classic factors. There are still many other factors that play a role in the etiology of melasma, as ingredients in cosmetics, drugs that are phototoxic, endocrine disease, liver disorders, and nutritional deficiency. Important to note that most cases of melasma in men and third in women are idiopathic. [28]

In this study there is no significant correlation between MDA levels with severity of melasma ( $p>0.05$ ), but there is a tendency of increasing severity of melasma in higher levels of MDA. (Table 6) This is consistent with the results of research by Seckin et al (2013) that failed to show a significant relationship between levels of serum MDA with MASI values $(p>0.05)$. [12]

Oxidative stress is an imbalance between prooxidant state with antioxidant, because ROS formation exceeds the ability of the antioxidant defense system, or decrease, or the constant state of antioxidant capability. Oxidative stress causes oxidative damage to the cells constituent such as DNA, proteins, lipids and sugar. [24] The lipid will produce lipid peroxidation in cellular membranes that later release DAG activation of PKC- $\beta$ to stimulate melanogenesis. $[7,8]$ Malondialdehyde is the end product of lipid peroxidation, and is one indicator of oxidative stress. [12] Malondialdehyde is a product of the oxidation of unsaturated fatty acids by free radicals and is also a component of cell metabolites produced by free radicals. Therefore, a high concentration of MDA indicates oxidation processes in the cell membrane. The negative effects of free radicals can be mitigated by antioxidants either in the form of vitamins $\mathrm{A}, \mathrm{C}$, and $\mathrm{E}$, or antioxidants such as flavonoids and ginggerol. Therefore, the high and low levels of MDA relies heavily on the antioxidant status in the body of a person. [24]

This study found no significant correlation between the severity of melasma with MDA levels as in research Sari, et al (2014) because this study did not find any association between the severity of melasma with sun exposure. MDA levels increased as a result of sun exposure. In addition, measuring the severity of melasma with MASI score rely on examiner judgement, thus it can be affected by subjectivity of the examiner, which can generate different result.

The weakness of this study is the examination of MDA level was taken from patients' blood serum samples, where the levels of MDA in blood serum are influenced by several factors. Some of the factors that can affect are an oxidative stress in the human body that comes from exogenous and endogenous factors. Exogenous factors derived from chemotherapy treatment, environmental pollution, proinflammatory cytokines, sun exposure, and ionizing radiation. Endogenous factors derived from cytochrome P450, lipooksigenase, mitochondrial, metabolic processes, NADH oxidase, and peroxisomes, and the factor of natural antioxidant defence system which consist of enzymatic antioxidant such as catalase, glutathione peroxidase and superoxide dismutase and non-enzymatic antioxidant such as vitamin A, vitamin C, and vitamin E. [29] Another drawback in this study, which is we have no information about the last time of subject exposed to the sun when we draw the blood, and thus it is unknown whether levels of MDA were examined comes from sun exposure or not. MDA is the end product of lipid peroxidation, which is continuously formed but very easily metabolized. $[30,31]$

\section{Conclusion}

Free radicals can be formed as a result of exposure to sunlight, but the duration of sun exposure did not affect the severity of melasma. There is no significant correlation between MDA and the severity of Melasma. However, there is a tendency that as the MDA level increases, so as the severity of melasma. Therefore, the severity of melasma is influenced by several factors, not just from exposure to sunlight. The future research with Kohort design and larger sample were needed and MDA level may be more obvious if examined directly on the lesion tissues shortly after exposure to the sun.

\section{References}

[1] Sarkar, R., Arora, P., Garg, VK, Sonthalia, S. \& Gokhale, N. Melasma Update. Indian Dermatol Online J. 2014; 5: 426-35.

[2] Gupta, AK, Gover, MD, Nouri, K. \& Taylor, S. The treatment of melasma: A review of clinical trials. $J$ Am Acad Dermatol, 2006; 55: 1048-65.

[3] Soepardiman, L. Melasma. In: PERDOSKI, KSDKI (ed.) Symposium, Demo, Training and Exhibition of Cosmetic Dermatology Everything about skin pigmentation. Jakarta: KSDKI.. 2009.

[4] Handel, AC, Miot, LDB \& Miot, HA. Melasma: a clinical and epidemiological review. An Bras Dermatol, 2014; 89: 771-82.

[5] Sheth, VM \& Pandya, AG. Melasma: A comprehensive update Part I. J Am Acad Dermatol, 2: 011; 65: 689-97.

[6] Roberts, WE. Melasma. In: Kelly, AP \& Taylor, SC (eds.) Dermatology for Skin of Color. 1 ed. New York: McGrawHill; 2009. 
[7] Shweta, K., Khozema, S., Meenu, R., Anupama, S., SK, S. \& Neelima, S. A Systemic Review on Melasma: A Review. Int $J$ Cur Bio Med Sci.,. 2011; 1: 63-8.

[8] Park, H.-Y. \& Yaar, M.. Biology Of melanocytes. In: Goldsmith, LA, Katz, SI, Gilchrest, BA Paller, AS, Leffel, DJ \& Wolff, K. (eds.) Fitzpatrick's Dermatology in Genereal Medicine, 8th ed. New York: McGraw-Hill; 2012

[9] Krajcovicova-Kudlackova, Paukova, M., Bacekova, V. \& Dusinska, M.. Lipid peroxidation in relation to vitamin $\mathrm{C}$ and vitamin E levels. Cent. Eur. J. Publ. Health, 2004; 12: 46-8.

[10] Jetawattana, S. Malondialdehyde (MDA), a lipid oxidation product. Free Radicals in Biology and Medicine,. 2005; 77: 110.

[11] Hamadi, Mohammed, SA, Mahammed, Aljaf, M., N., A. \& ALI, A. The Role of Topical and OralMelatonin in Management of Patients Melasma Journal of Arab Universities for Basic and Applied Sciences. 2009; 8: 30-42.

[12] Seckin, HYLZ, Kalkan, GK, Bas, YN, Akbas, A., nder, YNO, Zyurt, HSO \&, Sahin, M. Oxidative stress status in Patients with melasma. Cutan Ocul Toxicol. 2013; 33: 212-17.

[13] Sari, AAIAN. Positive Correlation between Levels of malondialdehyde Serum with Melasma Area And Severity Index. Magister, Udayana University. 2014.

[14] Bhor, U. \& Pande, S.. Scoring systems in dermatology. Indian J Dermatol Venereol Leprol, 2006; 72: 315-21.

[15] Pandya, A. G., Lindas.Hynan, Bhore, R., Riley, F. C., Guevara, I. L., Grimes, P., Nordlund, J. J., Rendon, M., Taylor, S., Gottschalk, R. W., Agim, N. G. \& Ortonne, J.-P. Reliability assessment and validation of the Melasma Area and Severity Index (MASI) and a new modified MASI scoring method. $J$ Am Acad Dermatol. 2011; 64: 78-83.

[16] Ortonne JP, et al.. "A global survey of the role of ultraviolet radiation and hormonal influences in the development of melasma." JEADV 2009; 23: 1254-62.

[17] Rikyanto. 2004. The customer profile cases of melasma in cosmetic clinic of the Yogyakarta hospitals. Perdoski [Internet]. Available

at:www.perdoski.or.id/index.php/public/information/mdvidetail-content/87.

[18] Febrianti T, Soedarmono A, Rata IGAK, Bernadette I. 2004. Epidemiology of melasma in the outpatients clinics department of dermatology and venereology Cipto Mangunkusumo Hospital. 2004. Perdoski [Internet]. Available at: www. Perdoski.or Id. /index.php/public/information/mdvidetail-content $/ 86$.
[19] Baumann, L. \& Saghari, S. Skin Pigmentation and Pigmentation Disorders. In: Baumann, L. (ed.) Cosmetic Dermatology Principles and Practices. 2nd ed. New York: Mc-Graw Hill; 2009.

[20] Goh, CL., Dlova, CN. A retrospective study on the clinical presentation and treatment outcome of Dermatological melasma in a tertiary referral center in Singapore. Singapore Med J.1999; 40: 455-8.

[21] Tamler, C., Fonseca, RRR, Pereira, FBC, Barcaul, CB. Classification of melasma by dermoscopy: comparative study with Wood' s lamp. Surgical and Cosmetic Dermatology. 2009; 13: 115-9.

[22] Kim, NH, Oliviera, MC, Brain, RP, Marghoob, AA, Rabinovits, HS. Atlas of dermoscopy. Marghoob, AA, Malvehy, J., Braun, RP: United Kingdom; 2012.

[23] Hindritiani, R. Melasma. In Wasitaatmadja, S. (eds): Skin Pigmentation. Study Group of Cosmetic Dermatology Indonesia, 114-125; 2015.

[24] Winarsih, H. Natural Antioxidants and Free Radicals, Jogjakarta, Canisius; 2007.

[25] Diaconu, RE., Macarie, AE., Orasan, R. The Analysis of of oxidative stress in the sun-exposed and unexposed skin. Human and Veterinary Medicine, 2014; 6: 153-7.

[26] Costin, G.-E. \& Hearing, VJ. Human skin pigmentation: melanocytes modulate skin color in response to stress. FASEB J.2007; 21: 976-94.

[27] Miranti, A., Anwar, AI., Djawad, K., Patellongi, I., Wahab, S., Abdullah, N. The analysis of the estradiol hormone to several risk factors melasma. Magister, University of Hasanuddin; 2016.

[28] Damevska, K. New aspects of melasma. Serbian J Dermatol Venereol.2014; 6: 5-18.

[29] Rahman, T., Hosen, I., Islam, MMT., Sekhar, HU. Oxidative stress and human health. Adv Biosci. Biotechnol., 2012;3: 9971019 .

[30] Palmieri, B. \& Sblendorio, V. Oxidative stress tests: overview on reliability and use part 1. Eur Rev sMed Pharmacol Sci., 2007; 11: 309-42.

[31] Ayala, A., Munoz, MF., Arguelles, S. Lipid peroxidation: production, metabolism, and signaling mechanisms of malondialdehyde and 4-hydroxy-2-neonal. Oxid Med Cell Longev. 2014; 5: 1-31. 